\title{
8
}
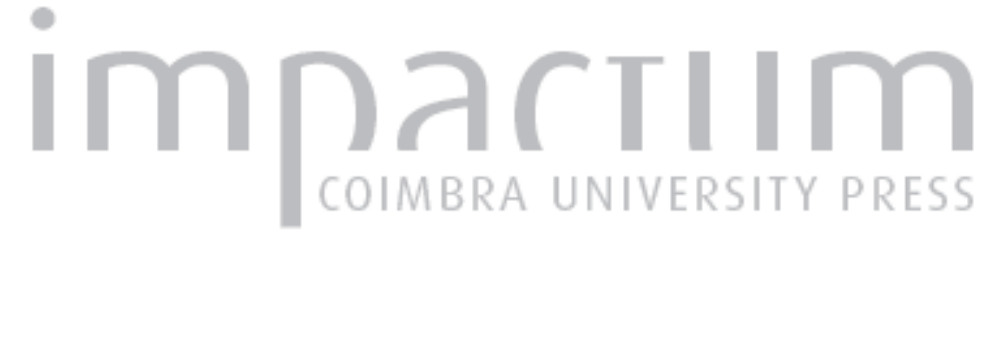

\section{Espaço vivido e saúde: contributos merleau-pontyanos para um debate}

\author{
Autor(es): Umbelino, Luís António
}
Publicado por: Faculdade de Letras da Universidade de Coimbra, Instituto de Estudos Filosóficos

URL persistente:

URI:http://hdl.handle.net/10316.2/33459

DOI:

DOI:http://dx.doi.org/10.14195/0872-0851_33_11

Accessed : $\quad$ 26-Apr-2023 10:55:21

A navegação consulta e descarregamento dos títulos inseridos nas Bibliotecas Digitais UC Digitalis, UC Pombalina e UC Impactum, pressupõem a aceitação plena e sem reservas dos Termos e Condições de Uso destas Bibliotecas Digitais, disponíveis em https://digitalis.uc.pt/pt-pt/termos.

Conforme exposto nos referidos Termos e Condições de Uso, o descarregamento de títulos de acesso restrito requer uma licença válida de autorização devendo o utilizador aceder ao(s) documento(s) a partir de um endereço de IP da instituição detentora da supramencionada licença.

Ao utilizador é apenas permitido o descarregamento para uso pessoal, pelo que o emprego do(s) título(s) descarregado(s) para outro fim, designadamente comercial, carece de autorização do respetivo autor ou editor da obra.

Na medida em que todas as obras da UC Digitalis se encontram protegidas pelo Código do Direito de Autor e Direitos Conexos e demais legislação aplicável, toda a cópia, parcial ou total, deste documento, nos casos em que é legalmente admitida, deverá conter ou fazer-se acompanhar por este aviso.

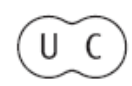




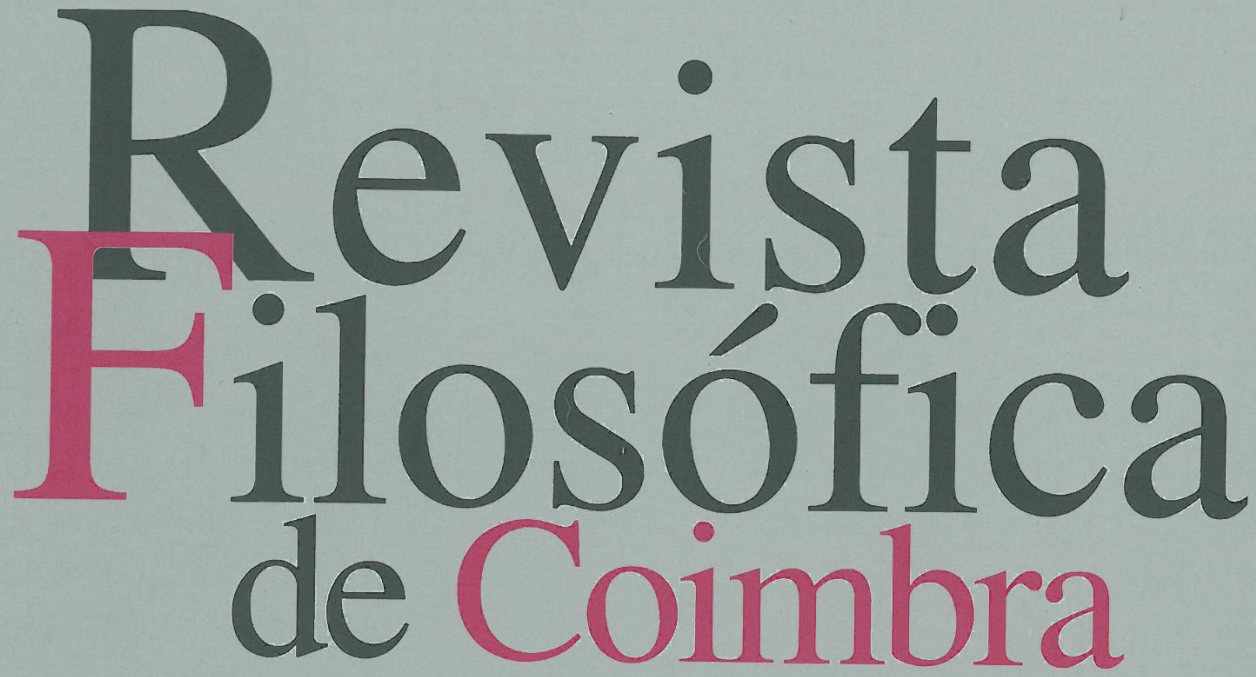

vol.17| n. .33 | 2008

Mário Santiago de Carvalho Fernanda Bernardo Luís António Umbelino Jean-Christophe Goddard Rui Alexandre Grácio Artur Ramos Luís M. Augusto Maria Luísa Portocarrero Jérôme Porée Diogo Ferrer Cláudio Alexandre Carvalho 


\section{ESPAÇO VIVIDO E SAÚDE. CONTRIBUTOS MERLEAU-PONTYANOS PARA UM DEBATE. \\ LUÍS ANTÓNIO UMBELINO \\ (Universidade de Coimbra)}

Resumo: Guardando o carácter de esboço e os traços de oralidade exigidos pela ocasião que o motivou, o pequeno texto que agora se apresenta procura meditar, no contexto específico de uma reflexão sobre "corpo, saúde e espaço público", a categoria de "espaço vivido".

1.

Começo com uma história minha, que, no entanto, manterei silenciosa. Direi apenas que se passou num hospital e se inscreveu nos arquivos da memória em redor de uma questão dolorosa: a de alguém próximo que pergunta, no desejo de regressar à saúde, quando poderá voltar para casa. Pergunta por tantos certamente já formulada, tantas vezes ouvida e recebida com dolorosa impotência; pergunta de alguém que entende a saúde com o nome de um espaço familiar. Como explicar derradeiramente essa experiência de espaço que, no questionar premente e doloroso, longe de se esgotar em considerações de localização ou medida, alberga o sentido profundo de morada - e de uma morada que se recorda, se sonha e se aguarda como promessa de Saúde?

A nosso ver, a força de uma tal questão confronta-nos imediatamente com uma evidência irrefutável: há uma experiência intensiva, vivida, do espaço, experiência irredutível a qualquer consideração calculadora, mas próxima do mistério da saúde. Importa meditá-la.

2.

Surpreendemos a experiência vivida do espaço em ocasiões específicas que parecem interceptar as vivências quotidianas. São os ápices em que 
afirmamos confusamente de uma rua que nos oprime, de uma sala que nos atrofia, de um jardim que nos descansa, de uma praia que nos liberta ou nos faz regressar às mais harmoniosos paisagens da memória. Os exemplos poderiam multiplicar-se: a sensação de "aridez" emanada de um espaço que parece gritar a nossa exclusão, a frequência penosa de um lugar empobrecido, a certeza de ser inundado pela memória dos lugares "nos quais os destinos do homem que habita ganham contornos na hora de uma estadia", o acolhimento súbito de um lugar que nos embarga com a promessa de todos os possíveis. Por igual fazemos, então, a experiência de "fazer parte" do espaço. E, no mesmo momento, comprovamos um facto: para além de uma distância física ou geométrica que existe entre nós e as coisas (característica da vulgar concepção de espaço como extensão mensurável e objectiva), uma proximidade vivida une-nos aos lugares que contam, aos lugares que nos aparecem, efectivamente, banhados de autenticidade e carregados de expectativa.

Ao espaço, pois, une-me um laço de conivência, um laço de silencioso conluio - laço do qual o corpo apenas parece deter o saber primitivo e justo.

O filósofo francês M. Merleau-Ponty viu bem o que deste modo se enuncia e não se furtou a uma meditação necessária sobre o espaço vivido de um corpo próprio. Em Phénoménologie de la perception tal consideração é central. A experiência corporal do espaço, prévia a qualquer consideração sobre forma ou conteúdo ${ }^{2}$, é entendida como fonte de um saber pré-temático sobre a realidade profunda quer do espaço que se habita, quer do corpo que se é. Dito de outro modo, há um saber do corpo que apenas se encontra no modo de estar no espaço e há um saber do espaço que apenas se pode encontrar no modo de ser corpo.

Não é um pormenor que sob a pena do filósofo francês tal aparente mútua inscrição convoque os modelos do jogo, do sonho, do mito, do poético. Como corpo, estou no espaço como num jogo: jogando-o na exacta medida em que sou jogado; estou no espaço como num sonho: sonhando o que se sonha em mim sem controlo; estou no espaço, enfim, percorrendo não qualquer distância geométrica, mas vivendo intensivamente uma realidade que apenas se decifra no poético e se narra numa história simbólica. Pretende-se expressar, nestes termos, que a questão do espaço deve ser compreendida como relação de coexistência pela qual

${ }^{1}$ HEIDEGGER, H., Questions IV, (trad. francesa) Gallimard, Paris, 1976, pág. 101$-102$.

2 Cf. MERLEAU-PONTY, M., Phénoménologie de la Perception, Gallimard, 1945, pág. 278. 
aquele que pensa o espaço compreende que pertence desde sempre a isso que pensa. O que não é dizer pouco. A realidade do espaço encontra-se, para aquém de qualquer esquema mensurável e quantitativo, num entrecruzamento originário firmado por um laço invisível mas, todavia, profundamente familiar e concreto ao corpo que sou. Dito de outro modo: a verdade derradeira do "nosso" espaço ou "solo perceptivo" subsiste numa zona não-temática, que o sentido de uma interpenetração com o sujeito que habita corporeamente o mundo e é, de algum modo, por este igualmente habitado - como se fosse vivido pelo espaço.

Para Merleau-Ponty, podemos afirmá-lo, a experiência de embricamento, decisiva para estabelecer o ponto de partida para um saber do espaço, não pode ser considerada apenas como dimensão psicológica ou sociológica. Do que se trata é, antes, de considerar o próprio modo corporal de habitar o mundo, de estar enraizado no meio das coisas. Estamos imersos - e não, justamente, sobrevoando ou apenas localizando objectos num ponto determinado de uma extensão mensurável, configurada por um conjunto de relações quantitativas de distância ou grandeza - num espaço que se parece arrolar em nós através de cada lugar de presença.

O "como" de tal inscrição não é fácil de esclarecer por força da sua parte de inacabado. Mas podemos supor que tudo se passa como se uma reflexividade do espaço procurasse firmar - e assim revelar - um irreflectido do corpo e, em contrapartida, a interpretação de si do sujeito corpóreo fosse sempre pré-reflexivamente descentrada, espalhada e obrigada a passar pela diferença do que envolve, situa e sugere o modo próprio de existir como corpo. O irreflectido do corpo será, então, ícone de um irreflectido do espaço e vice-versa. Dito de outro modo, a nossa condição corporal - de um corpo próprio - não começa, nem acaba nas fronteiras do corpo físico, do mesmo modo que a realidade do espaço que habitamos não se detém nas fronteiras orgânicas do corpo mas o invade e nele se prolonga numa pluralidade de extensões e intensidades. Como Mereau-Ponty havia sublinhado, deve afirmar-se que, incrustados no espaço, não sabemos sempre e em cada momento onde acaba o corpo e começa o mundo; e é essa mistura que, em rigor, funda verdadeiramente a nossa situação e determina o sentido vivido de "ter um lugar de onde" se percebe.

Neste contexto tudo se passa como se as fronteiras do local geométrico implodissem recorrentemente e o espaço físico se descentrasse por intermédio das mais variadas dilatações, dispersões, pulsações, retracções. Percebemo-lo sempre em esgueire quando, por exemplo, experimentamos a sala onde escutámos uma música impar "dilatar-se", "abrir-se" ou "encher-se" com a melodia; quando sentimos a distância que nos separa de um lugar de encontro "aumentar" sem porquê; quando, conduzindo o 
nosso carro por uma passagem estreita, inconscientemente encolhemos os braços no seu interior como se todas as distâncias fossem desposadas pelo corpo; quando, enfim, ante o espectáculo de uma paisagem estonteante como que descobrimos que é o espaço que nos "ensina a olhar" (no sentido em nenhum aparecer espacial é possível sem receber de quem vê e oferecer a quem vê, não uma soma de objectos mas todo o espaço). Dir-se-ia, em cada um destes exemplos, que a pertença ao espaço é caracterizada pelo "escorregar" do espaço físico para uma não-coincidência consigo mesmo, ou mais precisamente, pela "metamorfose" do espaço físico, através de um estranho sistema de trocas, no solo vivido de um corpo expressivo e significante - corpo que não está apenas no espaço homogéneo mas habita a filigrana de um espaço ante-predicativamente familiar.

Do que falamos é de uma relação de mútua pertença, de mútua invasão, ou, como dirá Merleau-Ponty, de quiasma. E, com ela, o que se demonstra não é senão um aparecer do espaço que, na sua realidade mais profunda, se revela irredutível quer a propriedades objectivas das coisas e sua topologia geométrica, quer a um qualquer decreto do sujeito. $\mathrm{O}$ que nas pequenas e grandes experiências de coexistência o que se deve então compreender é, justamente, a que ponto corpo e espaço parecem nascer, no mesmo momento, um do outro.

\section{3.}

A este respeito será, eventualmente, o pintor quem primeiro conhece por dentro tal experiência e, por essa razão, quem mais nos poderá elucidar. Cézanne, por exemplo, sublinha Merleau-Ponty, afirmava sentir-se germinar com a paisagem ${ }^{3}$, nascer em cada pedaço de natureza. Compreendia, deste modo, a condição primitiva sobre a qual o seu gesto de interpretação pictórica se poderia confirmar: deixar ser a paisagem, numa disponibilidade para o que interpela, para o que, literalmente, inspira à procura de expressão. Por isto, a mais não almejava o pintor enamorado pelas cores de Aix-au-Provance do que a devolver à natureza os seus direitos - a essa natureza, a esse espaço que o convocava insistentemente e sem descanso, como se apenas no corpo que pinta encontrasse o local certo para aceder à expressão do seu próprio sentido que, de outro modo, permaneceria condenado à mudez.

${ }^{3}$ MERLEAU-PONTY, «Le doute de Cézanne», in ID, Sens et non-sens, Nagel, Paris, 1966, p. 29. 
Cézanne não ignorou o essencial desse pacto que manteve toda a sua vida com o que está aí para pintar. Disse-o numa formulação lapidar que merece ser levada a sério: "a paisagem pensa-se em mim e eu sou a sua consciência." Afirma-o depois de reconhecer o carácter segundo, derivado, ilusório, das relações espaciais de grandeza ou distância da perspectiva tradicional; sente-o na necessidade de abraçar o vigor da "perspectiva vivida" - dessa "perspectiva" tomada pelo "interior" e estruturada sobre uma profundidade que não se projecta porque é o próprio tecido do espaço, sobre um movimento que não é mensurável, sobre um tempo que não é cronológico. Ora, o que na procura da perspectiva vivida o pintor igualmente descobre, não é senão que o corpo que ele é se $f a z$ corpo que pinta no justo corresponder ao apelo insistente do visível; e isto no mesmo instante em que, do mesmo modo, o visível se faz a sua própria expressão no justo inspirar do corpo. Mais: no momento em que descobre o poder do corpo para habitar o espaço, descortina que tal poder tem como contrapartida secreta a capacidade - mais antiga - do espaço para espacializar o corpo. A "pré-posse" do corpo sobre o espaço, não é senão a "pré-posse" do espaço sobre o corpo.

\section{4.}

O conjunto das nossas experiências está desde sempre trespassado por uma espacialidade já adquirida - porque já oferecida - na qual nos descobrimos a acontecer numa atmosfera que é, por definição, não tematizável integralmente. Tal relação ou experiência de mútua pertença, já o referimos, não pode ser entendida, segundo Merleau-Ponty, como qualquer tipo de vivência psicológica ou como qualquer subjectivismo que interpretaria individualmente o recebido do exterior pelos sentidos. Este ponto é importante. Também porque suscita uma questão: como compreender então, e de modo último, o que vem sendo afirmado? Note-se, primeiro, um detalhe decisivo: o que Merleau-Ponty nos propõe pensar não é algo vivido, mas $o$ vivido, não apenas o modo como vivemos o espaço, mas o modo como o espaço nos vive. Levar a sério tais evidências exige que se suplante qualquer resquício do primado da consciência e se aprofunde a análise num sentido radical. É o que Merleau-Ponty faz ao propor a seguinte possibilidade de análise: levemos às últimas consequências a experiência de estar mergulhado no espaço e aceitemos que nos une ao espaço um "pacto profundo", ou uma "ligação concreta";

\footnotetext{
${ }^{4}$ ID, idem, p. 30.
} 
de que outro modo poderíamos explicar tal junção, tal união senão, precisamente, afirmando que entre corpo e espaço (corpo e visível, corpo e natureza) não há verdadeiramente qualquer separação, mas continuidade? Resta pensar essa continuidade. Levemo-la a sério: o que descobrimos senão que corpo e espaço devem partilhar um mesmo estofo, uma mesma textura, um mesmo "Ser" - uma mesma Carne?

Apenas no contexto deste aprofundamento a tradicional cisão entre interior do corpo e exterior do espaço perde, definitivamente, qualquer significado. Em rigor o "interior" do corpo nada é de diferente do "exterior" de um espaço englobante; e o "exterior" deste espaço prolonga-se pelo "interior" do corpo. Isto no sentido em que, para o corpo que não deixo de ser, estar no espaço não significa, enfim, apenas ocupar um lugar determinado: mais do que localizado no espaço, o corpo mistura-se nele, mais do que olhá-lo de frente partilha com ele uma mesma textura ontológica, mais do que percebê-lo "ali", pertence ao momento da sua deflagração. Assim, que o espaço seja o vivido - em cada momento-lugar intensivo, no modo como o espaço e o corpo mutuamente se tomam a cargo - guarda um significado radical que importa libertar: corpo e espaço mantêm uma relação de comunicação mais velha do que o pensamento (e que escapa a qualquer exercício de precisão estabelecida sobre o conhecimento desinteressado de relações espaciais entre objectos), relação que se esclarece apenas no plano de uma endo-onto-topologia da Carne - de uma Carne que é Espaço, na medida em que o processo de fenomenalização do Ser é igualmente espacialização do espaço e consequente espacialização do corpo enquanto dobra da mesma Carne. Assim se entenderá a tese nuclear que Merleau-Ponty fixa no magnífico texto Le philosophe et son ombre: "pode dizer-se literalmente que o próprio espaço se sabe através do meu corpo."5

A pertença carnal do corpo ao Espaço - desse corpo que, como disse P. Valéry, se empresta ${ }^{6}$ ao mundo para o transformar em pintura - obriga a considerar toda uma necessária revolução "anti-antropocêntrica". Merleau-Ponty reconheceu bem essa necessidade que encontra expressa nas obras de muitos artistas. De André Marchand destaca a seguinte frase, onde ecoa a influência de P. Klee: "Senti, em certos dias, que eram as árvores que me olhavam, que me falavam... Eu estava lá à escuta ...Creio que o pintor deve ser trespassado pelo universo, e não querer trespassálo..."7. Nada que o nosso Pessoa não tivesse dito com a garra do génio:

5 MERLEAU-PONTY, M., «Le philosophe et son ombre», in ID, Éloge de la philosophie et autres essais, Gallimard, Paris, p. 257.

${ }^{6}$ ID, L'oeil et l'esprit, Gallimard, Paris, 1964, p. 16.

${ }^{7}$ ID, idem, p. 31. 
"Não sou eu quem descrevo. Eu sou a tela / E oculta mão colora alguém em $\operatorname{mim}(\ldots) "$.

É incrustado no espaço e por ele preenchido de inscrições espacializantes, é frequentando-o e integrando o $\mathrm{fora}^{8}$ como o outro lado do seu próprio interior, é virtualizando-se na sua filigrana, que o corpo revela enfim a sua própria textura intensiva, excessiva, pessoal, ex-istencializada - e a revela como o fio vidente-visível, espacializante-espacializado do Ser que "separa e reúne, que sustém toda a coesão", como fio da Carne entretecida de uma profundidade, movimento e tempo que urge compreender uma derradeira vez em cada experiência de entrelaçamento.

\section{5.}

Somos um corpo feito de espaço. E só por isso somos igualmente um corpo feito de tempo. É ainda o espaço que, segundo Merleau-Ponty, sustém "mesmo o passado e o futuro", porque o tempo, enfim, nada seria fora dessa espacialidade fundamental que encontra no corpo o topos do seu redobramento. Mesmo ao nível da vivência corporal do espaço, não se poderá negar que o espaço "vivido" é já sempre também um espaço que se "narra", um espaço que se conta; e se conta na medida "incomensurável" em que conta a nossa própria história.

Os lugares habitados, justamente, são aqueles onde o vivido se inscreveu e deixou a sua marca indestrutível nos arquivos da memória. Neles o "habitado" cruza-se com o "construído" e amplifica-o. Considere-se o lar de um leitor, organizado em função da arrumação dos livros, moldado pelo crescimento da biblioteca que permanece história viva nas escolhas e leituras de cada época; tenha-se em conta a sala de estar do melómano, organizada laboriosamente em função do fruir musical, que se recorda em cada disco. Cada um destes lugares narra a história do seu inquilino - e cada objecto arrumado no seu sítio, cada gesto de "construção" do conforto, é um capítulo dessa história.

Se quisermos explicá-lo derradeiramente seguindo ainda as indicações e propostas de Merleau-Ponty, deveríamos começar por reconhecer que nessas experiências se comprova algo importante: que o espaço se pensa

${ }^{8}$ Cf. MALDINEY, H., “À l'écoute de Henri Maldiney, a propos de corps et architecture », in YOUÈNES, C., NYS, Ph. E MANGEMATIN, M., (dir.), L'Architecture au Corps, Ousia, Bruxelles, 1997, p. 18. Cf. ainda RICHIR, M., "Corps, espace et architecture", in ID, idem, p. 24.

${ }^{9}$ MERLEAU-PONTY, M., L'oeil et l'esprit, o. c., p. 85. 
no corpo muito antes do corpo pensar o espaço. Deveríamos reconhecer seguidamente que esse espaço não é estranho ao tempo e recorda a própria Carne do mundo de que o corpo é dobra. Efectivamente, será necessário considerar que uma "eternidade" do percebido abarca cada presente como interior - e não, precisamente, exterior - a todos os que já foram. Assim apenas se poderá notar o aqui decisivo: o significado de considerar que "algo" se pode dizer "já ter sido".

Merleau-Ponty recorre a uma formulação interessante para considerar a questão: "ao virem ao visível as coisas inscrevem uma sombra delas mesmas que é indelével" 10 . Essa sombra não é uma simples recordação ou imagem; antes um "passado-sombra", ou passado "vertical", onde cada presente guarda o seu poder de irradiação. Passado e presente formam um todo de diferentes que não se anulam mas permanecem um junto do outro, um dentro do outro, um em redor do outro. Assim se explica, notou bem Paul Claudel, que as nossas recordações não sejam ordenadas cronologicamente segundo uma clareza decrescente. Muitas vezes acontecimentos "mais antigos" são recordados - ressuscitados - como "mais presentes". Assim é, segundo Merleau-Ponty, porque estão inscritos num mesmo Espaço onde o seu "fantasma" permanece - não por relação a uma ideia ou a uma consciência, mas por diferenciação na própria Carne do Sensível. O mesmo Sensível de que o corpo é fio de espaço e de memória.

\section{6.}

Corpo que vive e é vivido pelo espaço, por isso, igualmente o lugar onde o tempo acontece, sou um corpo-espaço que é campo de futuro e de passado. A memória de um espaço perdido prova a mútua pertença do corpo e do espaço a um mesmo esquema temporal. Essa mútua pertença encontra nos movimentos do corpo, nas suas des-locações e localizações, bem como na organização, construção e preenchimento dos lugares, eixos que lhe permitem fixar-se e redobrar-se. Um cheiro, um som, uma melodia, um objecto familiar não deixam de existir num espaço físico, mas minam-no, investem-no, deslocam-no num mesmo momento em que convocam todo o corpo de um modo especial. Aí apenas, nos lugares que nos acolhem integralmente, que vibram as cordas de uma harmonia que nos faz perseverar por todo o lado e em parte alguma, aí apenas, dizíamos, se conta a história do corpo que sou na coesão (narrada) de uma vida.

${ }^{10}$ MERLEAU-PONTY, M., Le visible et l'invisible, Gallimard, Paris, 1964, pp. 170 e ss. 
Somos nos lugares onde corpo e espaço se reconhecem unidos, como que nascendo em simultâneo um do outro; somos nos lugares "construídos" e "habitados" como nossos e com os nossos, onde irrompe a certeza de uma co-pertença profunda. Como ignorar, então, que o espaço seja também questão do mistério da saúde? 